Bull. Chem. Soc. Ethiop. 2007, 21(1), 95-102.

Printed in Ethiopia

ISSN 1011-3924

(c) 2007 Chemical Society of Ethiopia

\title{
ETHYLMETHYLDIOXIRANE EPOXIDATION OF PLUKENETIA CONONOPHORA
} OIL

\author{
E.T. Akintayo* \\ Chemistry Department, University of Ado-Ekiti, P.M.B. 5363, Ado-Ekiti, \\ Ekiti State, Nigeria
}

(Received January 13, 2006; revised March 31, 2006)

\begin{abstract}
Epoxidation of Plukenetia conophora oil by ethylmethyldioxirane has been studied. The epoxidation reaction was best accomplished using the Curci's biphasic method employing 2butanone as the solvent. Spectroscopic techniques (IR, ${ }^{1} \mathrm{H}$ NMR and ${ }^{13} \mathrm{C} N M R$ ) indicated complete conversion of double bonds to epoxy groups. Overall, Oxone ${ }^{\mathrm{TM}}$ can be said to be an inexpensive oxidant that is easily handled and with demonstrated utility in preparing epoxidised oils from natural triglycerides.
\end{abstract}

KEY WORDS: Plukenetia conophora oil, Epoxidation, Ethylmethyldioxirane, Oxone ${ }^{\mathrm{TM}}$

\section{INTRODUCTION}

Vegetable oils are renewable raw materials that possess certain frictional properties like good lubricity, low volatility, high viscosity index, solvency for lubricant additives and easy miscibility with other fluids [1]. The high degree of unsaturated fatty acids in the composition of many vegetable oils however causes them to have low thermal and oxidative stability thereby restricting their use as lubricants, stabilizers and plasticisers. One of the major chemical ways of improving the oxidative and thermal stability of oil is by epoxidation. Epoxidised fatty acids are employed as lubricants [2]. Epoxidised soybean oil, linseed oil and octyl oleate are used mainly as plasticisers and stabilizers in polyvinylchloride. They add flexibility to the polymer and scavenge any hydrogen chloride that is liberated by heat and light [3]. Vegetable oils are usually converted to epoxidised materials on large scale by using hydrogen peroxide and formic acid or acetic acid [3]. These reactions are usually very exothermic and therefore carry along with them inherent concerns about safety. There is also the corrosion problem caused by the acidity of the percarboxylic acids used and also by acids formed by reduction of the peracids during the epoxidation process. Furthermore the epoxides prepared by these methods must be instantly separated from the acids to avoid the oxirane ring opening which leads to lower oxirane value. It has also been generally observed that peracid oxidation of unsaturated vegetable oils do not appear to go to completion [4-6]. To circumvent these problems Sonnet and Foglia [7] suggested the use of dioxiranes. Dioxiranes are cyclic peroxides. Such compounds have been postulated as intermediates in reactions involving peracids [8]. Murray [9] described various methods that have been used to prepare and isolate different dioxiranes. Dioxiranes have been proven to be powerful oxygen transfer reagents and their chemistry has been described as that of electrophillic oxidants [8]. Sonnet and Foglia [7] reported the epoxidation of some vegetable oils using ethylmethyldioxirane (EMDO) and recorded a good success by generating and using EMDO directly in biphasic systems in presence of a phase transfer catalyst. With the advent of epoxy resins, epoxy plasticizers, epoxy stabilizers and epoxy insecticides, epoxy compounds generally have assumed an unprecedented importance. Epoxidised soybean oil accounts for about the total epoxidised ester production with only minor contributions from linseed, rapeseed, olive, corn and safflower oil [5].

*Corresponding author. E-mail: temitopeakintayo@yahoo.com 
Plukenetia conophora (PKCP) of family Euphorbiacae is a climbing shrub that is common in the South-Western part of Nigeria. The seeds are eaten like walnuts often with rice. The leaves are edible and are often eaten with rice. The oil content of the seeds is high $(49.58 \%)$ and the oil has been found to consist of $70.1 \%$ linolenic, 17.05 linoleic, $11.7 \%$ oleic, $0.6 \%$ stearic and $0.8 \%$ palmitic acids [10]. For such oil with very high level of unsaturation and in particular high content of linolenic acid, peracid epoxidation is inappropriate [11]. This work aims at investigating the effectiveness of ethylmethyldioxirane as an oxidant for epoxidising PKCP oil. The epoxidised oil was subsequently characterized by spectroscopic techniques. The potential use of such epoxidised oil includes the areas of coatings, lubricants and plastics.

\section{EXPERIMENTAL}

\section{Materials}

All reagents were purchased from Merck (Darmstadt, Germany) and used as received. Plukenetia conophora (PKCP) seeds were purchased from Erekesan market in Ado-Ekiti, Ekiti state, Nigeria. Bad seeds were removed by hand picking. The good seeds were washed with water and air dried and later milled using Christy mill. Oven dried samples $\left(103{ }^{\circ} \mathrm{C}\right)$ were extracted by Soxhlet method using n-hexane. Solvent was removed under reduced pressure in a rotary evaporator. The crude oil was refined by agitating with $18 \mathrm{M} \mathrm{NaOH}(1: 30 \mathrm{~g} / \mathrm{g}$ of alkali:powder) for $15 \mathrm{~min}$. The resultant mixture was heated to $75-80{ }^{\circ} \mathrm{C}$ to break the soap stock and the neutral oil separated by centrifugation.

\section{Biphasic oxidation of Plukenetia conophora oil}

$20.3 \mathrm{~g}$ of PKCP oil (iodine value $=140 \mathrm{mg} \mathrm{KOH} / \mathrm{g}$; oxirane value $=0$ ) was dissolved in $200 \mathrm{~mL}$ of ethylmethylketone and the mixture was vigorously stirred with $65.6 \mathrm{~g}(780 \mathrm{mM})$ of $\mathrm{NaHCO}_{3}$ and $5 \mathrm{~g}$ of tetrabutylammonium chloride, the phase transfer catalyst (PTC). A solution of Oxone $^{\mathrm{TM}}$, monopotassium peroxosulphate $(132 \mathrm{~g}, 215 \mathrm{mM})$ in $750 \mathrm{~mL}$ of water was added gradually in two parts 15 min apart. The reaction flask was wrapped in foil to protect against light. After complete addition of the Oxone ${ }^{\mathrm{TM}}$, the reaction was allowed to proceed for another $30 \mathrm{~min}$, after which the reaction mixture was diluted with water $(1 \mathrm{~L})$ and extracted $3 \times 100 \mathrm{~mL}$ portion of diethyl ether. The combined organic extract was washed with water and dried over anhydrous $\mathrm{Na}_{2} \mathrm{SO}_{4}$. The solvent was removed in vacuo. The yield of the epoxidised PKCP was $18.5 \mathrm{~g}$. the epoxidised oil had iodine value $=1.5 \mathrm{mg} \mathrm{KOH} / \mathrm{g}$ and oxirane value $=5$.

\section{Spectroscopic analysis}

IR spectra of the PKCP oil and epoxidised PKCP oil (liquid) were recorded on a Fourier transform Infrared Spectrometer, Tensor 27 FT/IR - H1026302 (Bruker Optik, GmbH, Germany). The frequency and intensity of each band was obtained automatically by using the 'find peak' command of the instrument OPUS software.

${ }^{1} \mathrm{H}$ NMR and ${ }^{13} \mathrm{C}$ NMR spectra of samples dissolved in deuteriated chloroform were recorded on a Bruker Avance-400 (Bruker instruments, Inc. Karlsruhe, Germany) Fourier transform spectrometer operating at $400.6 \mathrm{MHz}$ and $100.6 \mathrm{MHz}$ for ${ }^{1} \mathrm{HNMR}$ and ${ }^{13} \mathrm{CNMR}$, respectively. The gated decoupling pulse sequence was used with the following parameters; number of scans 512, acquisition time $1.366 \mathrm{~s}$, pulse width $10.3 \mu \mathrm{s}$, free induction decay was transformed and zero filled to $300 \mathrm{~K}$ to give digital resolution of $2 \mathrm{~Hz} /$ point. 
Gas chromatography

Fatty acid methyl esters of the ordinary oil and the epoxidised oil were prepared by shaking 50 $\mathrm{mg}$ of sample dissolved in $10 \mathrm{~mL}$ of toluene with $0.2 \mathrm{~mL}$ of tetramethyl ammonium hydroxide (TMAH). $4 \mathrm{~mL}$ of water was added the mixture was allowed to settle, and $1 \mu \mathrm{L}$ of the toluene layer injected into a Hewlett Packard GC (model CP 9000) equipped with split/splitless injection port and flame ionization detector and fitted with a $\mathrm{J} \& \mathrm{~W}$ scientific fused silica column $\mathrm{DB} 5,25 \times 0.25 \mathrm{~mm}, \mu_{\mathrm{f}}=0.25 \mu \mathrm{m}$. The injection port and detector temperatures were $250{ }^{\circ} \mathrm{C}$ and $280{ }^{\circ} \mathrm{C}$, respectively. The oven temperature was programmed as follows; $120{ }^{\circ} \mathrm{C}$ for $3 \mathrm{~min}$, then temperature increased at $4{ }^{\circ} \mathrm{C} / \mathrm{min}$ till $260{ }^{\circ} \mathrm{C}$ and held for $5 \mathrm{~min}$. Identification of the peaks was done on a Hewlett Packard HP 5973 Mass Spectrometer (mass selective detector) interfaced with a HP 6890 series GC (Agilent Technologies, Waldron, GmbH). The mass spectrometer parameters used were electron impact energy $70 \mathrm{eV}$, transfer line $270{ }^{\circ} \mathrm{C}$, source temperature $250{ }^{0} \mathrm{C}$, emission current $0.5 \mathrm{~mA}$, cycle time $0.6 \mathrm{sec} / \mathrm{scan}$ from 45 to 400 a.m.u., electron multiplier voltage $1.7 \mathrm{kV}$ and pre-amp sensitivity $10^{-7} \mathrm{Amp} / \mathrm{V}$.

\section{Physico-chemical analysis}

Iodine value (IV) was determined according to standard procedures [12]. Oxirane value (OV) was determined titrimetrically as described by Durbetaki [13].

\section{RESULTS AND DISCUSSION}

Dioxiranes, 1, have proven to be a very powerful and versatile oxygen atom transfer reagent [10] and their chemistry is best described as that of electrophillic oxidants. Dioxiranes have been prepared by reaction of ketones with aqueous slurries of sodium bicarbonate and Oxone ${ }^{\mathrm{TM}}$ (monopotassium peroxosulphate) as solutions in parent ketones [14]. Such solutions have been employed to conduct oxidations of diverse classes of organic compounds. In this work we have employed the Curci's biphasic procedure, [8], where the dioxirane is generated in-situ and used directly. In this procedure a water insoluble ketone is employed as both dioxirane reagent and organic solvent along with a phase transfer catalyst (PTC). Preliminary investigation revealed that of several ketones, ethylmethyl ketone functioned best. The reactions involved in the preparation of ethyl methyl dioxirane (EMDO) and its subsequent oxidation of the triglyceride of PKCP are summarized in Schemes 1 and 2, respectively.

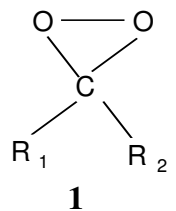

1

$$
\begin{array}{ll}
\text { 1 a. } & \mathrm{R}_{1}=\mathrm{R}_{2}=\mathrm{CH}_{3} \\
\text { 1b. } & \mathrm{R}_{1}=\mathrm{CH}_{3}, \quad \mathrm{R}_{2}=\mathrm{CF}_{3} \\
1 \mathrm{c} & \mathrm{R}_{1}=\mathrm{CH}_{3}, \quad \mathrm{R}_{2}=\mathrm{CH}_{3} \mathrm{CH}_{2}
\end{array}
$$

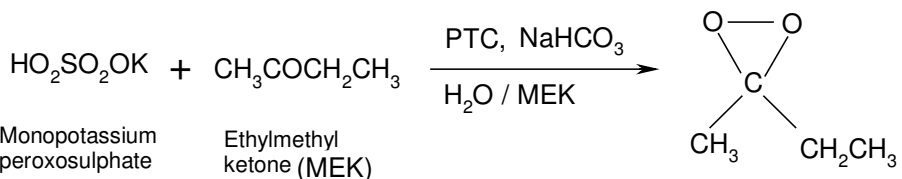

peroxosulphate ketone (MEK)

Scheme 1

Ethylmethyl dioxirane (EMDO)

Bull. Chem. Soc. Ethiop. 2007, 21(1) 

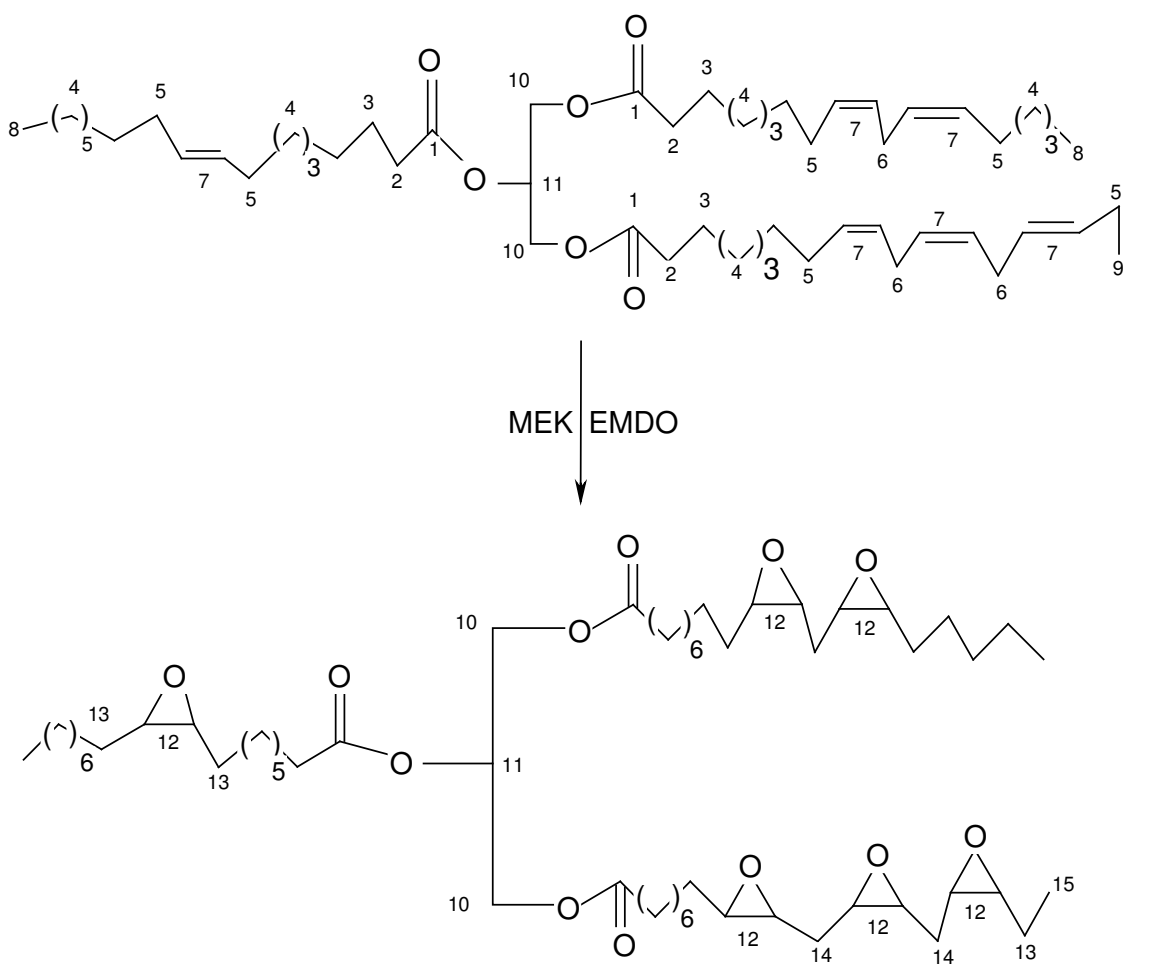

Scheme 2

The infrared spectra of the ordinary and epoxidised PKCP oil are presented in Table 1. Both oils show the characteristic C-H stretching mode between $2800-3000 \mathrm{~cm}^{-1}$. In the epoxidised oil the highest frequency of absorption of this group attributed to the vinyl $\mathrm{C}-\mathrm{H}$ is absent. This indicates the total absence of vinyl groups in the epoxidised oil. Common to both oils are the carbonyl absorption at $1742 \mathrm{~cm}^{-1}$, the characteristic triglyceride ester triplet at 1240,1158 and $1106 \mathrm{~cm}^{-1}$ and the sharp absorption at $724 \mathrm{~cm}^{-1}$ assigned to $\mathrm{C}-\mathrm{H}$ bending of saturated carbon chain more than seven carbon atoms long. The epoxidised oil in addition to the above showed a distinct doublet absorption at $823 \mathrm{~cm}^{-1}$ characteristic of the C-O-C oxirane stretch usually observed in the naturally epoxidised vegetable oils [15]. The absence of hydroxyl band in the IR spectra of the epoxidised PKCP oil indicates the superiority of the dioxirane epoxidation of triglyceride over the peracid epoxidation which has been noted to cause oxirane ring opening to the diols $[6,16]$.

The peak assignments of the proton NMR spectra of the oils are presented in Table 2. There are two sets of peaks from $4.0-4.4 \mathrm{ppm}$ produced by the four methylene protons on the glycerol centre while the peak at $5.25 \mathrm{ppm}$ is produced by the $\beta$-methine proton of glycerol. The peaks at 5.3-5.5 ppm are produced by the protons on double bonds. The peaks in the region 2.2-2.3 ppm indicate the presence of methylene groups next to carboxyl group. Peaks in the region 2.7-2.8 ppm correspond to methylene groups surrounded by double bonded carbon atoms. The huge peak at 1.2-1.4 is due to methylene groups surrounded by single bonded atoms. Presence of linolenic acid is indicated by the peak at $0.97 \mathrm{ppm}$ corresponding to the terminal homoallylic methyl groups of n-3 polyunsaturated fatty acids (PUFA). The chemical shift is slightly more 
downfield than other terminal methyl signals at $0.88 \mathrm{ppm}$ which appears in saturated and non n-3 PUFA. The ${ }^{1} \mathrm{H}$ NMR spectra of the epoxidised PKCP oil reveals that the double allylic proton $=\mathrm{CCH}_{2} \mathrm{C}=$ present in the ordinary oil at $2.7-2.8 \mathrm{ppm}$ is completely absent and a new band attributable to epoxy- $\mathrm{CH}_{2}$-epoxy occurs in the epoxidised oil at around $1.7 \mathrm{ppm}$. In the same manner, the peak at $0.97 \mathrm{ppm}$ indicating the presence of linolenic acid (attributable to terminal methyl homoallylic in linolenate glyceride) present in the ordinary oil is absent in the epoxidised while a new peak occurrs at 1.0-1.1 due to terminal methyl of a triepoxystearate. The epoxidised oil also has no olefinic proton signals in the region 5.2-5.3 ppm, but shows the epoxy protons in 2.8-3.2 ppm region.

Table 1. IR frequencies of PKCP oil and ethylmethyldioxirane epoxidised PKCP oil.

\begin{tabular}{|c|c|}
\hline PKCP oil cm & -1 \\
\hline 3007.07 & Epoxidised PKCP oil cm \\
2923.14 & - \\
2853.48 & 2924.26 \\
1744.27 & 2854.75 \\
1463.07 & 1742.28 \\
1377.13 & 1463.54 \\
1237.11 & 1378.41 \\
1160.99 & 1238.34 \\
1104.04 & 1156.34 \\
- & 1108.22 \\
722.09 & 823.70 \\
579.76 & 729.11 \\
\hline
\end{tabular}

Table 2. Peak assignments of the ${ }^{1} \mathrm{H}$ NMR spectra of ordinary and ethylmethyldioxirane epoxidised PKCP oil.

\begin{tabular}{|c|c|c|c|}
\hline Proton & Absorption region & $\mathrm{n}(\mathrm{ppm})$ & Assignment \\
\hline 2 & $2.3-2.4$ & $(\mathrm{t}, 2 \mathrm{H})$ & $-\mathrm{C}_{2} \mathrm{COO}^{-}$ \\
\hline 3 & $1.6 \quad($ & $(\mathrm{m}, 2 \mathrm{H})$ & $-\mathrm{C}_{2}-\mathrm{C}-\mathrm{COO}-$ \\
\hline 4 & $1.2-1.4$ & $(\mathrm{~m}, 2 \mathrm{H})$ & $-\underline{\mathrm{CH}}_{2}-\mathrm{C}$ \\
\hline 5 & $1.95-2.1$ & $(\mathrm{~m}, 2 \mathrm{H})$ & $-\mathrm{C} \overline{\mathrm{H}}_{2} \mathrm{C}=$ \\
\hline 6 & $2.7-2.8$ & $(\mathrm{dd}, 2 \mathrm{H})$ & $=\overline{\mathrm{CC}} \underline{\mathrm{H}}_{2} \mathrm{C}=$ \\
\hline 7 & $5.3-5.4$ & $(\mathrm{~m}, 1 \mathrm{H})$ & $=\mathrm{C} \underline{\mathrm{H}}$ \\
\hline 8 & 0.85 & $(\mathrm{t}, 3 \mathrm{H})$ & Terminal methyl \\
\hline 9 & 0.97 & $(\mathrm{t}, 3 \mathrm{H})$ & Terminal methyl homoallylic in linolenic fatty acid \\
\hline 10 & $4.2-4.4$ & $(\mathrm{~d}, 2 \mathrm{H})$ & Glycerol methylenes \\
\hline 11 & $5.2-5.3$ & $(\mathrm{~m}, 1 \mathrm{H})$ & Glycerol methine \\
\hline 12 & $2.9-3.3$ & $(\mathrm{~m}, 1 \mathrm{H})$ & Epoxy protons \\
\hline 13 & 1.5 & $(\mathrm{~m}, 2 \mathrm{H})$ & $\mathrm{C}_{2}-$ - epoxy \\
\hline 14 & 1.7 & $(\mathrm{dd}, 2 \mathrm{H})$ & Ероху $-\mathrm{CH}_{2}-$ ероху \\
\hline 15 & $1.0-1.1$ & $(\mathrm{t}, 3 \mathrm{H})$ & Terminal methyl of triepoxystearate \\
\hline
\end{tabular}

${ }^{13} \mathrm{C}$ NMR of the ordinary oil (Table 3.) presents peaks at 172-173 ppm (C-1); 125-133 ppm $(\mathrm{C}=\mathrm{C}), 62 \mathrm{ppm}(\mathrm{C}-3$ of esterified glycerol); $68 \mathrm{ppm}$ (C-2 of esterified glycerol); 14-31 ppm (various $\mathrm{CH}_{2}$-). ${ }^{13} \mathrm{C}$ NMR of epoxidised PKCP oil (Table 3) shows all these except for the signal between 125-133 ppm and in addition presents new peaks between 56-58 ppm ascribable to epoxy ring carbons. The absence of olefinic signals between 125-133 ppm further confirms the virtually complete epoxidation of the PKCP oil. 
Table $3 .{ }^{13} \mathrm{C}$ NMR chemical shifts in ppm of PKCP oil and ethylmethyldioxirane epoxidised PKCP oil.

\begin{tabular}{|c|c|}
\hline PKCP oil $(\mathrm{ppm})$ & Epoxidised PKCP oil $(\mathrm{ppm})$ \\
\hline 173.196 & 173.131 \\
172.789 & 172.723 \\
131.891 & - \\
129.957 & - \\
128.015 & - \\
127.055 & - \\
68.825 & 68.789 \\
62.047 & 61.980 \\
- & 57.079 \\
- & 54.257 \\
- & 54.104 \\
33.979 & 33.869 \\
31.869 & 31.740 \\
29.178 & 29.113 \\
27.149 & 27.717 \\
25.585 & 26.495 \\
24.780 & 24.676 \\
22.647 & 23.825 \\
20.509 & 22.552 \\
14.079 & 13.992 \\
\hline
\end{tabular}

The gas liquid chromatographic analysis of the methyl esters of ordinary and epoxidised PKCP oils (Figures 1 and 2.) indicated that the major unsaturated fatty acid, oleic, linoleic and linolenic had been consumed. An insignificant amount of epoxies of linoleic and linolenic acids appeared in the products. Overall the GLC results also confirmed the completeness of the epoxidation of PKCP oil using the Oxone ${ }^{\mathrm{TM}}$ reagent. The ethyl methyldioxirane oxidized PKCP oil was obtained as clear and colourless product. Physico-chemical analysis revealed that the iodine value (Wijs) and percentage oxirane of the epoxidised PKCP oil were $1.5 \mathrm{mg} \mathrm{KOH} / \mathrm{g}$ and 5.0 , respectively, compared to $140 \mathrm{mg} \mathrm{KOH} / \mathrm{g}$ and 0 in the starting oil.

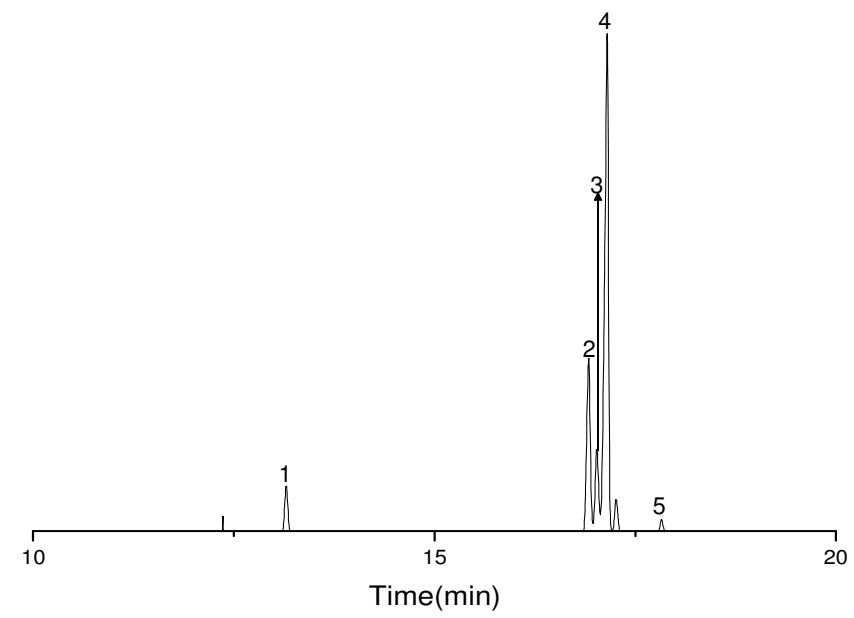

Figure 1. Chromatogram of methyl esters of PKCP oil. 1, C16:0; 2, C18:2; 3, C18:3; 4,C18:1; 5, C18:0.

Bull. Chem. Soc. Ethiop. 2007, 21(1) 


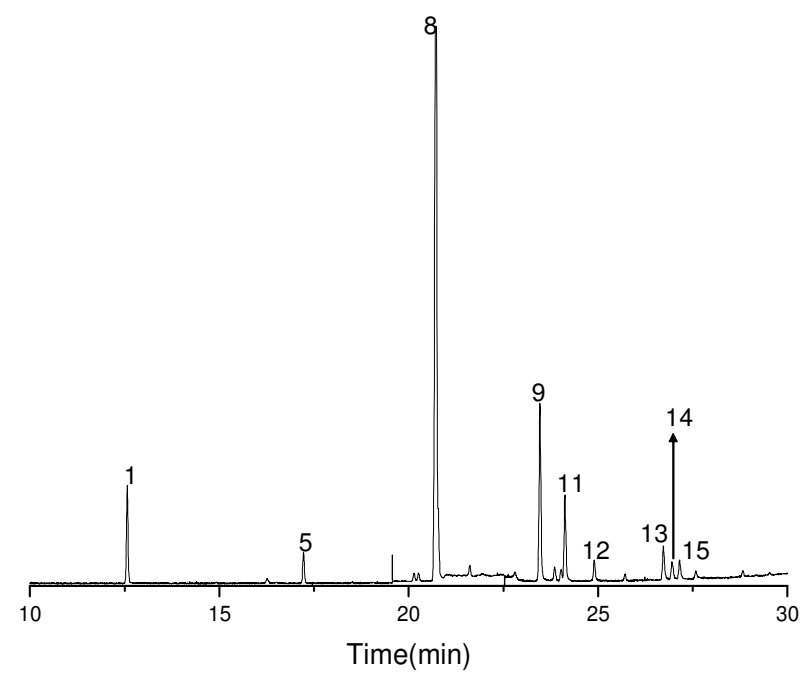

Figure 2. Chromatogram of methyl esters of ethylmethyldioxirane epoxidised PKCP oil. 1, C16:0; 5, C18:0; 6, monoepoxy-C18:1; 7,monoepoxy-C18:2; 8,monoepoxy-C18:0; 9, 10, 11, diepoxy-C18:0; 12, diepoxy-C18:1; 3, 14, 15, triepoxy-C18:0.

\section{CONCLUSIONS}

Epoxidation of PKCP oil with high percentage composition of linolenic acid are effectively accomplished using the Curci's biphasic method employing ethylmethyl ketone as the solvent and ethylmethyl dioxirane as the oxidant. Spectroscopic and gas chromatographic methods indicated complete epoxidation of PKCP oil.

\section{REFERENCES}

1. Advaryu, A.; Erhan S.Z. Ind. Crops \& Products 2002, 15, 247.

2. Swern, D. (Ed.) Bailey's Industrial Oil and Fat Products, Vol. 2, 4th ed., John Wiley and Sons Inc: New York; 1982; p 367.

3. Gunstone, F.D.; Hamilton, R.J. (Eds.) Oleochemical Manufacture and Applications, Sheffield Academic Press: Sheffield, England; 2001; pp 14-24.

4. Gan, L.H.; Ooi, K.S.; Gan, L.M.; Goh, S.H. J. Am. Oil Chem. Soc. 1995, 72, 439.

5. Gan, L.H.; Goh, S.H.; Ooi, K.S. J. Am. Oil Chem. Soc. 1992, 69, 347.

6. Mageli, O.I.; Patteson, F.W.; Spenser, E.Y. Canadian J. Chem. 1952, 31, 23.

7. Okiemen, F.E.; Bakare, O.J.; Okiemen C.O. Ind. Crops \& Products 2002, 15, 139.

8. Murray, R.W.; Jeyaraman, R. J. Org. Chem. 1985, 50, 2847.

9. Murray, R.W. Chem. Rev. 1989, 89, 1187.

10. Akintayo, E.T.; Bayer E. Biores. Tech. 2002, 85, 95.

11. Sonnet, P.E; Foglia, T.A. JAOCS 1996, 73, 461.

12. DGF. German Society for Fat Science, German standard methods for the analysis of fats and other lipids, Wissenschaftliche Verlagsgesellschaft $\mathrm{mbH}$ : Stuttgart, Germany; 1994.

Bull. Chem. Soc. Ethiop. 2007, 21(1) 
13. Durbetaki, A.J. Anal. Chem. 1956, 28, 2000.

14. Sonnet, P.E.; Lankin, M.E.; McNeil, G.P. JAOCS 1995, 72, 199.

15. Ayorinde, F.O.; Butler, B.D.; Clayton, M.T. J. Am Oil Chem. Soc. 1990, 67, 844.

16. Curci, R.; Fiorentino, M.; Troisi, L. J. Org. Chem. 1980, 45, 4758. 